\title{
PENGARUH SUMBER DAYA ALAM LOKAL TERHADAP KOMPON KARET SOL SEPATU KANVAS UNTUK UMUM
}

\section{THE EFFECT OF LOCAL NATURAL RESOURCES OF CANVAS SHOE SOL COMPONENTS FOR GENERAL}

\author{
Rahmaniar ${ }^{*}$ dan Hari Adi Prasetya ${ }^{1}$ \\ ${ }^{*}$ main contributor and corresponding author \\ ${ }^{1}$ Balai Riset dan Standardisasi Industri Palembang, Kementerian Perindustrian, Indonesia \\ e-mail : rahmaniar_een@yahoo.co.id, hariadiprasetya@yahoo.co.id
}

Diterima: 23 Oktober 2019; Direvisi: 23 Oktober - 5 Desember 2019; Disetujui: 17 Desember 2019

\begin{abstract}
Abstrak
Penelitian ini bertujuan untuk menganalisa pengaruh campuran arang aktif serbuk gergaji dan pasir kuarsa sebagai filler dengan standar SNI 12-0172-2005 tentang Sepatu Kanvas untuk Umum. Desain penelitian ini dengan Rancangan Acak Lengkap (RAL), yaitu variasi perlakuan filler arang aktif serbuk gergaji dan variasi perlakuan filler pasir kuarsa, dengan ukuran partikel 400 mesh. Adapun konsentrasi variasi filler arang aktif serbuk gergaji yaitu 10 phr, 20 phr, 30 phr, 40 phr dan 50 phr dan variasi filler pasir kuarsa yaitu 50 phr, 40 phr, 30 phr, 20 phr dan 10 phr. Hasil uji vulkanisat karet kompon dengan bahan pengisi arang aktif serbuk gergaji dan pasir kuarsa diperoleh nilai terbaik pada perlakuan $\mathrm{C}$ (variasi arang aktif serbuk gergaji $30 \mathrm{phr}$ dan pasir kuarsa $30 \mathrm{phr}$ ). Karakteristik vulkanisasi untuk perlakuan $\mathrm{C}$ adalah : S.Max : 17,77 kg/cm, S.Min : 0,44, S.Max-S.Min : 17,33 kg/cm, Opt. Cure time (t90) : 12,51 menit dan scorch time (ts $\left.{ }^{2}\right)$ : 3:04 menit. Kompon yang dihasilkan juga memiliki nilai perpanjangan putus 428\% memenuhi SNI 12-0172-2005 (Min $100 \%$ ), Density 1,16 g/ $\mathrm{cm}^{3}$ memenuhi SNI 12-0172-2005 (Mak 1,5 g/ $\mathrm{cm}^{3}$ ) dan menghasilkan uji visual tidak ada cacat. Penambahan arang aktif serbuk gergaji cenderung menurunkan sifat perpanjangan putus dan density.
\end{abstract}

Kata kunci : Bahan pengisi, serbuk gergaji, pasir kuarsa, karet alam.

\begin{abstract}
This study aims to analyze the effect of a mixture of activated charcoal from sawdust and quartz sand as a filler with SNI 12-0172-2005 on Public Canvas Shoes. The research design used was Completely Randomized Design (CRD), namely variations in the treatment of sawdust active charcoal fillers and variations in the treatment of quartz sand fillers, with a particle size of 400 mesh. The concentration of active charcoal powder filler variation is $10 \mathrm{phr}, 20 \mathrm{phr}, 30 \mathrm{phr}, 40 \mathrm{phr}$ and $50 \mathrm{phr}$ and quartz sand filler variation is $50 \mathrm{phr}, 40 \mathrm{phr}, 30 \mathrm{phr}, 20 \mathrm{phr}$ and $10 \mathrm{phr}$. The results of compound rubber volcanic test with active ingredients of charcoal sawdust and quartz sand obtained the best value in treatment $C$ (variation of activated charcoal sawdust $30 \mathrm{phr}$ and quartz sand $30 \mathrm{phr}$ ). Vulcanization characteristics for treatment $C$ are: S.Max: 17.77 kg / cm, S.Min: 0.44, S.Max-S.Min: $17.33 \mathrm{~kg} / \mathrm{cm}$, Opt. Cure time (t90): 12.51 minutes and scorch time (ts2): 3:04 minutes. The resulting compound also has a break extension length of 428\% which meets SNI 12-0172-2005 (Min 100\%), Density $1.16 \mathrm{~g} / \mathrm{cm}^{3}$ meets SNI (Mak $1.5 \mathrm{~g} / \mathrm{cm}^{3}$ ) and produces no defective visual test. The addition of sawdust activated charcoal tends to decrease the breaking and density extension properties.
\end{abstract}

Keywords: Fillers, sawdust, quartz sand, natural rubber. 


\section{PENDAHULUAN}

Sepatu kanvas pada umumnya digunakan sebagai sarana olahraga, namun ada juga yang digunakan untuk pemakaian umum atau sehari-hari. Bagian atasannya dibuat dari bahan tekstil dengan diberi warna tertentu, sedangkan bagian bawah (sol) terbuat dari bahan karet atau plastik. Bagian yang terpenting dari sepatu adalah bagian telapaknya (sol), karena telapak sepatu harus dapat melindungi kaki dari permukaan jalan yang panas, basah dan kasar serta dari benda-benda tajam. Sifat alas kaki yang diinginkan pemakai yaitu tidak kaku, fleksibel sehingga nyaman untuk dipakai, memiliki sifat mekanik yang baik sehingga dapat digunakan untuk waktu yang lama (Emiliana, et al, 1993; Rahmawati, 2009).

Pembuatan barang jadi karet, seperti sol sepatu kanvas untuk umum merupakan salah satu upaya meningkatkan nilai tambah karet alam dan mengembangkan industri berbasis karet alam dalam negeri. Barang jadi karet dihasilkan dari kompon karet yang merupakan campuran antara karet alam dengan bahan-bahan kimia diantaranya bahan pengisi. Carbon black (CB) merupakan bahan pengisi yang secara umum digunakan. CB sebagai bahan pengisi penguat untuk meningkatkan sifat mekanik. CB mempunyai keunggulan, dimana ukuran butir molekulnya halus sehingga mempermudah dispersi partikel ke dalam matriks polimer. Keunggulan lain adalah ikatan Vander Wals antara CB dengan matriks polimer akan meningkatkan nilai kekerasan. Beberapa penelitian reinforcement filler terbarukan pengganti $C B$ seperti arang dari biomassa lignin (Setua et al, 2000), carbon dari sekam padi (Sae-Qui et al, 2002), abu/ampas tebu (Kanking et al, 2012) dan golongan mineral montmorilonite (Arroyo et al, 2003).

Bahan pengisi yang berasal dari sumber daya alam yang terbarukan dapat dijadikan alternatif pengganti bahan pengisi CB seperti arang sekam padi (Susanto dan Rahmaniar, 2019), Pati umbi gadung (Susanto dan Prasetya, 2016), arang serbuk gergaji (Purbaya dan Rahmaniar, 2016) dan arang aktif tempurung kelapa (Marlina et al, 2014).

Di dalam penelitian ini digunakan sumber bahan pengisi arang serbuk gergaji.
Arang serbuk gergaji merupakan limbah dari industri penggergajian kayu. Potensi serbuk gergaji dari indutri penggergajian kayu Indonesia adalah 0,78 juta $\mathrm{m}^{3}$ per tahun. Limbah serbuk gergaji ini jumlahnya cukup besar sehingga perlu dilakukan penanganan dan pemanfaatan yang lebih optimal sehingga zero waste limbah industri penggergajian dapat ditekan. Arang serbuk gergaji mengandung lebih dari $70 \%$ unsur $\mathrm{C}$ terikat (Pari dan Roliadi, 2009), sehingga dapat digunakan sebagai pengganti filler karbon hitam dalam pembuatan kompon karet. Bahan lain yang digunakan adalah pasir kuarsa. Pasir kuarsa mengandung kristal-kristal silika $\left(\mathrm{SiO}_{2}\right)$ berfungsi sebagai bahan pengisi (Hadi et al, 2010). Pasir kuarsa berasal dari bahan galian, dikenal dengan nama pasir putih, merupakan hasil pelapukan batuan. Hasil pelapukan kemudian tercuci dan terbawa oleh air atau angin yang terendap ditepi sungai, danau atau laut. Pasir kuarsa mengandung silika oksida $\left(\mathrm{SiO}_{2}\right)$ sebanyak 99,08\% (Sumarmo et al, 2015). Sebagai bahan pengisi pasir kuarsa dapat menambah kekuatan ikatan yang terjadi pada komponen barang jadi karet. Silika merupakan salah satu jenis bahan pengisi penguat non petroleum yang telah terbukti perannya sebagai bahan yang dapat menggantikan CB. Penggunaan silika harus diimbangi dengan penggunaan bahan pencepat saat vulkanisasi (Susanto dan Rahmaniar, 2019).

Berdasarkan karakteristik pasir kuarsa dan serbuk gergaji tersebut, maka dilakukan penelitian yang bertujuan untuk mengetahui pengaruh substitusi arang serbuk gergaji dan pasir kuarsa terhadap kompon karet untuk karet sol sepatu kanvas untuk umum, dalam penelitian ini pembuatan barang jadi karet menggunakan bahan pengisi arang aktif serbuk gergaji dan pasir kuarsa sekitar $32 \%$. Pengaruh penggantian filler dipelajari dengan memvariasikan jumlah (phr) masing-masing filler dengan ukuran partikel 400 mesh. Pengujian vukanisat dilakukan untuk parameter analisa Rheometer, perpanjangan putus, density dan uji visual. Sebagai pembanding digunakan persyaratan mutu menurut SNI 12-0172-2005 tentang sepatu kanvas untuk umum. Diharapkan dari hasil penelitian ini dapat menambah informasi baru bagi masyarakat khususnya para ilmuwan, 
peneliti dan masyarakat industri tentang alternatif bahan pengisi pengganti $C B$ yang ketersediaannya makin berkurang.

\section{BAHAN DAN METODA}

\section{Bahan}

Serbuk gergaji, diperoleh dari tempat penggergajian kayu (panglong) yang ada di Kota Palembang, $\mathrm{NaCl} 4 \%$, air, serbuk pasir kuarsa berasal dari didaerah Lahat, Standard Indonesia Rubber (SIR) 20, Zink Oksida (ZnO), Stearat Acid (SA), Anti Oksidan, N1,3-Dimethylbutyl-N-phenyl-p-

phenylenediamine (6-PPD), DPG, Oil, TMQ, Parafin Merkapto Dibenzothylazole Disulfida (MBTS), Tetra Metil Tiuram Disulfida (TMTD), dan Sulfur.

\section{Peralatan}

$\mathrm{pH}$ meter, Furnace, Sieve shaker, Crusher, Timbangan (Metler P1210), Open mill L $40 \mathrm{~cm}$ D18 cm kapasitas $1 \mathrm{~kg}$, Cutting scraft besar, Alat press, cetakan sheet, autoclave dan gunting.

\section{Metoda Penelitian}

Desain penelitian ini dilakukan dalam skala laboratorium dengan Rancangan Acak Lengkap (RAL), yaitu variasi perlakuan filler arang aktif serbuk gergaji (A) dan variasi perlakuan filler pasir kuarsa (B), ukuran arang aktif serbuk gergaji dan pasir kuarsa 400 mesh. Adapun konsentrasi variasi bahan pengisi, sebagai berikut :

a. Variasi filler arang aktif serbuk gergaji yaitu $10 \mathrm{phr}, 20 \mathrm{phr}, 30 \mathrm{phr}, 40 \mathrm{phr}$ dan $50 \mathrm{phr}$

b. Variasi filler pasir kuarsa yaitu $50 \mathrm{phr}, 40$ phr, 30 phr, 20 phr dan 10 phr

\section{Tahapan Penelitian : \\ Prosedur Penelitian}

\section{Pembuatan Filler}

- Pembuatan serbuk pasir kuarsa : pasir kuarsa dihaluskan dengan crusher kemudian diayak menggunakan sieve shaker untuk menghasilkan ukuran partikel 400 mesh.

- Pembuatan arang aktif serbuk gergaji

1) Proses karbonisasi dengan suhu $450^{\circ} \mathrm{C}$ selama 1 jam.

2) Arang hasil pirolisis diaktivasi dengan menggunakan $\mathrm{NaCl} 4 \%$ (direndam) selama 1 jam.
3) Arang dicuci dengan air beberapa kali sampai $\mathrm{pH}$ mencapai netral $\mathrm{pH}$ 7), lalu disaring dilanjutkan pirolisis suhu $500^{\circ} \mathrm{C}$ selama 1 jam dalam furnace.

4) Arang aktif digiling dan diayak menggunakan sieve shaker dengan ukuran partikel yang dihasilkan 400 mesh

Pembuatan Kompon Karet berdasarkan ASTM D3182 (Standard Practice for Rubber/Materials, Equipment, and Procedures).

\section{Penimbangan}

Bahan yang diperlukan untuk masingmasing formulasi kompon ditimbang sesuai perlakuan. Jumlah dari setiap bahan dalam formulasi kompon dinyatakan dalam satuan phr (per hundred rubber).

Tabel 1. Komposisi Kompon Karet dalam phr

\begin{tabular}{lccccc}
\hline Bahan & \multicolumn{5}{c}{ Formula } \\
& $\mathrm{A}$ & $\mathrm{B}$ & $\mathrm{C}$ & $\mathrm{D}$ & $\mathrm{E}$ \\
\hline SIR 20 & 100 & 100 & 100 & 100 & 100 \\
ZnO & 5.00 & 5.00 & 5.00 & 5.00 & 5.00 \\
Asam & 2.00 & 2.00 & 2.00 & 2.00 & 2.00 \\
Stearat & & & & & \\
Arang aktif & & & & & \\
serbuk & $\mathbf{1 0}$ & $\mathbf{2 0}$ & $\mathbf{3 0}$ & $\mathbf{4 0}$ & $\mathbf{5 0}$ \\
gergaji & & & & & \\
Pasir & $\mathbf{5 0}$ & $\mathbf{4 0}$ & $\mathbf{3 0}$ & $\mathbf{2 0}$ & $\mathbf{1 0}$ \\
kuarsa & & & & & \\
MBTS & 1.00 & 1.00 & 1.00 & 1.00 & 1.00 \\
DPG & 1.00 & 1.00 & 1.00 & 1.00 & 1.00 \\
Sulfur & 2.50 & 2.50 & 2.50 & 2.50 & 2.5 \\
6-PPD & 2.50 & 2.50 & 2.50 & 2.50 & 2.5 \\
Oil & 10.00 & 10.00 & 10.00 & 10.00 & 10 \\
TMQ & 1.50 & 1.50 & 1.50 & 1.50 & 1.5 \\
Total & $\mathbf{1 8 5 . 5}$ & $\mathbf{1 8 5 . 5}$ & $\mathbf{1 8 5 . 5}$ & $\mathbf{1 8 5 . 5}$ & $\mathbf{1 8 5 . 5}$ \\
\hline & & & & & \\
\hline
\end{tabular}

\section{Mixing (pencampuran)}

Proses pencampuran dilakukan dalam gilingan terbuka (open mill), yang telah dibersihkan, selanjutnya dilakukan proses:

1. Mastikasi Crumb rubber (SIR 20) selama 15 menit dan mencapai suhu $40-70^{\circ} \mathrm{C}$ dengan indikasi tidak ada lobang lagi yang terdapat pada karet yang sedang dimastikasi.

2. Pencampuran Karet Padat SIR 20 dengan bahan kimia diantaranya : $\mathrm{ZnO}$, giling bersama karet alam hingga $\mathrm{ZnO}$ sudah merata, dilanjutkan Asam Stearat, MBTS, DPG, TMQ, 6 PPD, filler, hingga campuran merata dan setelah merata campur oil, Sulfur, Setelah campuran sudah dianggap homogen, kemudian diblending sebanyak 6 kali. Pencampuran ini dilakukan juga untuk 
kompon yang lainnya sesuai dengan formula yang berikutnya.

\section{Parameter yang diamati}

Parameter yang diamati dalam penelitian ini meliputi karakteristik pematangan kompon, perpanjangan putus, density dan uji visual.

\section{HASIL DAN PEMBAHASAN}

\section{Karakteristik pematangan kompon}

Karakteristik vulkanisasi kompon meliputi torsi maksimum $\left(S_{\max }\right)$, torsi minimum $\left(S_{\min }\right)$, waktu pematangan optimum (t9o), dan waktu scorch $\left(\mathrm{t}_{\mathrm{s} 2}\right)$. Nilai torsi $\left(\mathrm{S}_{\max }\right.$, $S_{\text {min, }}$ ) memberikan gambaran ikatan silang yang terbentuk pada kompon baik secara fisika maupun secara kimia. Sedangkan waktu vukanisasi ( $t_{90}$ dan $t_{c 10}$ ) memberikan gambaran vulkanisasi secara kinetik (Tabaei et al, 2015). Nilai torsi minimum cenderung mengalami penurunan dengan pencampuran penambahan konsentrasi arang aktif serbuk gergaji dan penurunan konsentrasi pasir kuarsa (Tabel 2). Torsi maksimum ( $\left.S_{\max }\right)$ dapat digunakan untuk mengetahui viskositas maksimum dan kekakuan dari sampel yang telah mengalami vulkanisasi secara sempurna, nilai ini juga menunjukkan densitas ikatan silang yang terjadi (crosslink density) (Markovic et al, 2009). Delta torsi $(\Delta S)$ merupakan gambaran derajat ikatan silang (degree of crosslink) (Markovic et al, 2010).

Nilai torsi maksimum dan delta torsi meningkat dengan semakin meningkat nya penambahan konsentrasi arang aktif serbuk gergaji seiring dengan penurunan jumlah konsentrasi pasir kuarsa yang digunakan. Berdasarkan Tabel 2, waktu pematangan optimum ( $\left.\mathrm{t}_{90}\right)$ dan waktu scorch $\left(\mathrm{t}_{\mathrm{s} 2}\right)$ cenderung mengalami peningkatan dengan penambahan konsentrasi arang aktif serbuk gergaji seiring dengan penurunan jumlah konsentrasi pasir kuarsa yang digunakan.

Perlakuan C memiliki waktu pematangan yang paling singkat jika dibandingkan dengan perlakuan lainnya, sehingga perlakuan ini dapat menjadi perlakuan yang optimal dalam pembuatan formulasi karet sol sepatu kanvas untuk umum. Semakin naik penambahan arang aktif serbuk gergaji, maka pematangan kompon semakin memiliki waktu yang lama, sebaliknya dengan penambahan pasir kuarsa menyebabkan pematangan kompon semakin singkat. Penggunaan arang aktif serbuk gergaji dan pasir kuarsa ke kompon karet dapat meningkatkan kekerasan, kekuatan tarik, ketahanan sobek dan ketahanan kikis (Sari dan Jannah, 2017), hal ini dikarenakan pasir kuarsa secara teoritis mengandung $\mathrm{SiO}_{2}$ 97,13\% (Rahmaniar, et al, 2015). Sedangkan arang aktif serbuk gergaji mengandung 50\% karbon (Trihadi, 2003), sehingga dalam penelitian ini, komposit arang aktif serbuk gergaji dan pasir kuarsa diharapkan menjadi pengisi alternatif yang dapat mempersingkat waktu pemasakan kompon, meningkatkan sifat mekanik dan karakterisasi senyawa vulkanisasi.

Tabel 2. Karakteristik pematangan kompon

\begin{tabular}{|c|c|c|c|c|c|}
\hline $\begin{array}{l}\text { Sampel } \\
\text { kompon }\end{array}$ & $\underset{(\mathrm{Kg} / \mathrm{cm}}{\mathrm{S}_{\max }}$ & $\underset{(\mathrm{Kg} / \mathrm{cm}}{\mathrm{S}_{\min }}$ & $\begin{array}{c}\Delta \mathrm{S} \\
(\mathrm{Kg} / \mathrm{cm}\end{array}$ & $\begin{array}{c}\mathrm{t}_{90} \\
\text { (min, sec }\end{array}$ & $\begin{array}{c}\text { ts }_{2} \\
\text { (min,sec }\end{array}$ \\
\hline A & 15.45 & 0,23 & 15.22 & 12.49 & 3.47 \\
\hline B & 18.1 & 0,05 & 18.05 & 13.30 & 4.11 \\
\hline C & 17.77 & 0,44 & 17.33 & 12.51 & 3.04 \\
\hline D & 17.53 & 0,09 & 17.44 & 15.02 & 5.15 \\
\hline$E$ & 18.41 & 0,13 & 18.28 & 15.30 & 5.20 \\
\hline
\end{tabular}

\section{Sifat Mekanik Vulkanisat}

Berdasarkan hasil uji vulkanisat seperti yang tercantum pada Gambar 1, nilai perpanjangan putus (Elongation at break) semakin menurun dengan bertambahnya jumlah (phr) filler arang aktif serbuk gergaji, seiring dengan penurunan jumlah konsentrasi pasir kuarsa yang digunakan. $\mathrm{Hal}$ ini sesuai dengan hasil penelitian Yuniati et al, (2013) menyatakan bahwa penggunaan bahan pengisi arang aktif memberikan sifat mekanik yang lebih rendah dari pada karbon sintetis, namun karbon dari arang aktif serbuk gergaji mempunyai sifat dapat diperbaharui dan mempunyai sifat ramah lingkungan. Penurunan ini juga disebabkan adanya penurunan fleksibilitas jaringan polimer yang disebabkan adanya unsur karbon dari arang serta unsur silika dari pasir kuarsa, sehingga pengaruh filler penguat terlalu dominan.

Tingkat penguatan tergantung pada matriks polimer dan interaksi bahan pengisi (Chuayjuljit et al, 2002). Sifat mekanik menurun dapat berkaitan dengan penyebaran dari arang aktif serbuk gergaji, 
dimana pada saat konsentrasi arang aktif serbuk gergaji bertambah suatu keadaan dicapai partikel-partikel arang aktif serbuk gergaji membentuk suatu kumpulan (agregat) dan tidak lagi terdispersi secara merata pada karet alam. Pembentukan agregat dari arang aktif serbuk gergaji menurunkan luas bidang interaksi antara aktif serbuk gergaji dengan karet alam. Hal ini sesuai dimana semakin lemah daya interaksi keduanya maka semakin rendah pula sifat mekanik suatu vulkanisat tersebut (Surya, 2006).

Menurut Liu et al, 2008 ; Medalia, 1978; Sae-Qui et al, 2002, Nakason et al, 2001, Perpanjangan putus merupakan sifat utama dari kompon karet, merupakan manifestasi densitas ikatan silang dalam kompon dan keberhasilan filler dalam mempengaruhi kompon, filler reinforcement akan menguatkan kompon, sedangkan non reinforcement filler akan menurunkan sifat mekanik kompon. Sehingga densitas ikatan silang yang tinggi akan menaikkan elongation at break begitu sebaliknya. Elongation at break petunjuk atau indikator kekuatan dan kekenyalan karet yang artinya vulkanisat karet semakin elastis.

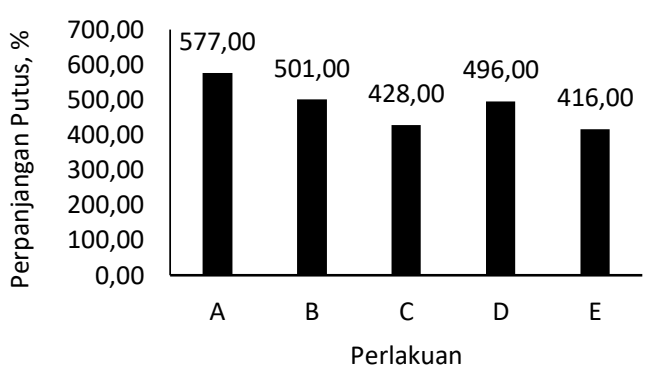

\section{Gambar 1. Hasil uji perpanjangan putus barang jadi karet}

Pengujian Berat Jenis (density, $\mathrm{gr} / \mathrm{cm}^{3}$ ) digunakan untuk mengontrol berat kompon yang akan digunakan untuk membuat vulkanisat karet dengan hitungan volume. Menurut Handayani (2008) pengukuran berat jenis juga bertujuan untuk mengawasi mutu dari kompon karet serta perhitungan jumlah karet yang dibutuhkan untuk volume tertentu. Berdasarkan hasil pengujian yang dilakukan terhadap kompon penelitian ini diperoleh hasil bahwa makin tinggi jumlah (phr) arang aktif serbuk gergaji, makin menurun nilai berat jenisnya dan cenderung tidak terjadi perbedaan angka yang signifikan setiap jumlah phr vulkanisat, nilai berat jenis kompon karet semakin kecil menunjukkan bahwa proses pematangan kompon semakin cepat. Penurunan berat jenis ini dapat dipengaruhi oleh peningkatan proporsi bahan pengisi (Herminiwati et al, 2003), sebaliknya peningkatan berat jenis disebabkan karena banyaknya molekul dalam senyawa silika $\left(\mathrm{SiO}_{2}\right)$ yang terikat pada polimer karet yang menjadikan kompon karet makin padat sehingga berat jenisnya makin besar, peningkatan berat jenis disebabkan karena makin banyak molekul yang terikat pada polimer karet menjadikan kompon karet makin padat, sehingga berat jenisnya makin besar (Supraptiningsih, 2005).

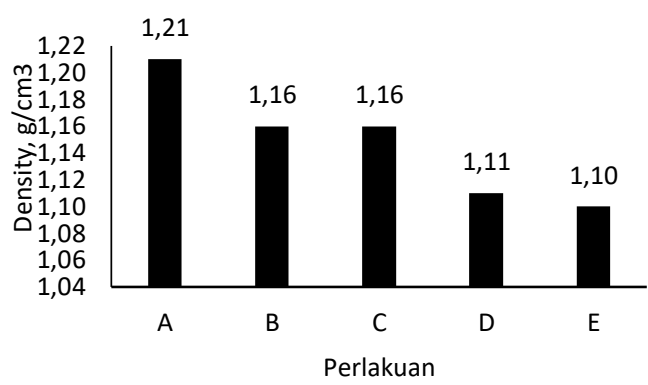

\section{Gambar 2. Hasil uji density barang jadi karet}

Pemeriksaan secara visual dilakukan terhadap kecacatan produk karet sepatu kanvas untuk umum yang dihasilkan dari formula A sampai dengan formula $E$. Nilai cacat dapat disebabkan karena pencampuran yang tidak merata, perbandingan penggunaan bahan baku dan bahan pembantu yang tidak proposional. Selain itu penggunaan temperatur pada saat pencampuran bahan tidak tepat sehingga vulkanisasi tidak terjadi secara maksimal. Pelepasan karet sepatu kanvas untuk umum dari cetakan (moulding) dapat menyebabkan cacat produk, jika tidak hati-hati. Uji visual untuk semua formula kompon vulkanisat yang dihasilkan dalam percobaan tidak terjadi kecacatan, berarti proses kompon berlangsung sempurna sesuai dengan kondisi operasi yang ditetapkan. Hal ini menunjukkan bahwa semua perlakuan dapat memenuhi standar persyaratan SNI 12-01722005 sepatu kanvas untuk umum. 


\section{KESIMPULAN}

Secara umum hasil uji vulkanisat karet kompon dengan bahan pengisi arang aktif serbuk gergaji dan pasir kuarsa diperoleh nilai terbaik pada perlakuan C (variasi arang aktif serbuk gergaji 30 phr dan pasir kuarsa 30 phr) dengan ukuran partikel 400 mesh memenuhi SNI 12-0172-2005.

Karakteristik vulkanisasi untuk perlakuan C adalah : S.Max : $17,77 \mathrm{~kg} / \mathrm{cm}$, S.Min : 0,44, S.Max-S.Min : 17,33 kg/cm, Opt. Cure time (t90) : 12,51 menit dan scorch time $\left(\mathrm{ts}^{2}\right)$ : 3:04 menit. Kompon yang dihasilkan juga memiliki nilai perpanjangan putus $428 \%$ memenuhi SNI (Min 100\%), Density $1,16 \mathrm{~g} / \mathrm{cm}^{3}$ memenuhi SNI (Mak 1,5 $\mathrm{g} / \mathrm{cm}^{3}$ ) dan menghasilkan uji visual tidak ada cacat.

\section{UCAPAN TERIMA KASIH}

Penulis mengucapkan terima kasih kepada Kepala Baristand Industri Palembang yang telah memfasilitasi riset ini, Putri Kurnia Sari, Yunita Rafiatul Jannah dan seluruh tim yang telah memberikan masukan dan bantuannya sehingga kegiatan penelitian ini dapat diselesaikan.

\section{DAFTAR PUSTAKA}

Arroyo, M., Lopez-Manchado, M., and Herrero, B., (2003). Organomontmorillonite as substitute of carbon black in natural rubber compound. Polymer, 44(8),2447-2453

Basseri, A., (2008). Pedoman Praktek Pengujian Fisika Karet Alam. Makalah Kursus Teknologi Barang jadi karet. Pusat Penelitian Karet, Bogor

Chuayjuljit, S., Eiumnoh, S., and Potiyaraj, P. (2002). Using Silica from Rice Husk as $A$ Reinforcing Filler in Natural Rubber. Journal of Science. 26(2): 127-138.

Emiliana K, Usodo, Sri Nadilah dan Penny Setyowari. (1993). Penelitian Pembuatan Kompon Karet untuk Sol dan Foxing Sepatu kanvas. Majalah Barang Kulit, Karet dan Plastik. Vol VIII No. 15.

Franta, I. (1989). Elastomers and Rubber Compounding Materials, Manufacture, Properties and Application. Elvevier, Amsterdam, Oxford, New York.

Hadi, Suratman dan Munatsir, T., (2010). Sintesis Silika berbasis Pasir Alam Bancar menggunakan Metoda Kopresitasi, 1-5. http://doi.org/10.12962/j24604682.v7i2.902.
Handayani, M. (2008). Pemanfaatan Karet Siklo dalam Rol Karet Gilingan Padi (Rice Huller Rubber). (Skripsi). Bogor: Fakultas Teknologi Pertanian Institut Pertanian Bogor.

Herminiwati, Purnomo, D., dan Supranto. (2003). Sifat Filler Kayu Kering terhadap Vulkanisat Karet. Majalah Barang Kulit, Karet dan Plastik 19(1): 32-39.

Kahar, N. (2003). Rapatan Ikatan Silang pada Karet Alam yang divulkanisir. Teknologi Indonesia. VIII(2).

Kanking, S., Niltui, P., Wimolmala, E., dan Sombatsompop, N., (2012). Use of bagasse fiber ash as secondary filler in silica or carbon black filler natural rubber compound. Materials and Design, 41, 74-82.

Liu, C., Shao, Y., and Jia, D. (2008). Chemically modified starch reinforced natural rubber composites. Polymer, 49(8), 2176-2181

Medalia, A. (2008). Effect of carbon black on dynamic properties of rubber vulcanizates. Rubber chemistry and Technology, 51(3) 437523

Marlina, P., Pratama, F., Hamzah, B., dan Pambayun, R. (2014). Pengaruh suhu dan lama penyimpanan terhadap karakteristik kompon karet dengan bahan pengisi arang aktif tempurng kelapa dan nano silika sekam padi. Jurnal Dinamika Penelitian Industri Vol. 25 No. 1 (43-51)

Mark, James E(2005). Science /and Technology of Rubber Third Edition.Elsevier : Amsterdam.

Markovic, G., Radovanovic, B., Marinovic-Cincovic, M., and Budinski-Simendic, J. (2009). The Effect of Accelerators on Curing Characteristics and Properties of Natural Rubber/Chlorosulphonated Polyethylene Rubber Blend. Materials and Manufacturing Processes, 24(10-11), 1224-1228.

Markovic, G., Samarzija-Jovanovic, S., Jovanovic, V., and Marinovic-Cincovic, M. (2010). Thermal Stability of CR/CSM Rubber Blends Filled with Nano and Micro-Silica Particles. Journal of Thermal Analysis and Calorimetry, 100(3), 881-888.

Nakason, C., Aesman, A., Homsin, S., dan Kiatkamjornwong, S. (2001). Rheological and curing behavior of reactive blending. Maleated Natural Rubber-cassava starch. Journal of Applied Polymer Science, 81(11), 2803-2813.

Purbaya, M., Rahmaniar (2018). Pemanfaatan arang serbuk gergaji dan minyak jarak untuk pembuatan sol karet cetak. Prosiding Seminar Nasional 1 Litbangyasa Industri. Baristand Industri Palembang

Pari, G dan Roliadi, H., (2009). Alternative technology for the utilization of biomass waste from wood industries. Proceeding of the 
International Workshop on better Utilization of Forest Biomass for Local Community and Envinronments, Research and Development centre for Forest Product Technology, Bogor

Rahmaniar, Amin Rejo, Gatot Priyanto dan Basuni Hamzah (2015). Karakterisasi Kompon Karet dengan Menggunakan Ekstrak Kayu Secang, Pasir Kuarsa dan Kulit Kerang, Jurnal Teknologi Industri Pertanian. 25 (3):227-238.

Rahmawati (2009). Pengaruh Komposisi Arang Cangkang Kelapa Sawit dan Hitam Arang (Carbon Black) Terhadap Kualitas Kompon Karet Sol Sepatu. Skripsi. Universitas Sumatera Utara. Medan.

Sari, P.K dan Jannah, Y.R.(2017). Pengaruh Komposisi Filler Campuran Arang Aktif Serbuk Gergaji dan Pasir Kuarsa Terhadap Sifat Fisik Kompon Karet Sol Sepatu. Laporan Penelitian. Jurusan Teknik Kimia. Fakultas Teknik. Universitas Sriwijaya.

Surya, I. (2006). Pengaruh Penambahan Pengisi Penguat terhadap Sifat Uji Tarik Karet Alam Terepoksida. Jurnal Teknik Simetrika. 1: 6874.

Setua, D., Shukla, M., Nigam, V., Singh, H., dan Mathur, G. (2000), Lignin reinforced rubber composites. Polymer Composites, 21(6), 988995.

Sae-Qui, P., Rakdee, C., dan Thanmathorn, P. (2002). Use of rice husk ash as filler in natural rubber vulcanizates: In comparison with other commercial fillers. Journal of Applied Polymer Science, 83(11), 2485-2493

Susanto, T dan Rahmaniar (2019). Pengaruh arang sekam padi dan pasir kuarsa sebagai bahan pegisi terhadap kualitas karet bantalan dermaga. Jurnal Dinamika Penelitian Industri Vol. 30 No. 1 Tahun 2019 (45-54)

Susanto, T., dan Prasetya, H. (2016). Kajian penggunaan pati umbu gadung termodifikasi sebagai subtituen Carbon Black pada pembuatan vulkanisat karet alam. Jurnal Dinamika Penelitian Industri Vol. 27 No. 2 (0918)

Suharman, Daud, D, Susanto, T., (2016). Mempelajari sifat fisika karet sol sepatu dari bahan pengisi arang batok kelapa. Prosiding Seminar Nasional Riset dan Industri. Balai Riset dan Standardisasi Industri Bandar Lampung (242-247).

Sumarno, Novarita, P., Januarty, M., dan Yuniarti, Y. (2015). Pemurnian Pasir Silika dengan Metoda Leaching Asam dan bantuan Sonikasi. Seminar Nasional Teknik Kimia Kejuangan. Surabaya: Institut Teknologi Sepuluh Nopember Surabaya.

Supraptiningsih, A. (2005). Pengaruh RSS/SBR dan filler $\mathrm{CaCO}_{3}$ terhadap sifat fisis Kompon Karpet Karet. Majalah kulit, karet dan Plastik. 21(1): 3.

Tabaei, T, A., Bagheri, R., and Hesami, M. (2015). Comparison of Cure Characteristics and Mechanical Properties of Nano and Micro Silica-Filled CSM Elastomers. Journal of Applied Polymer Science, 132(42), 1-11.

Trihadi,B. (2003). Pemanfaatan Limbah Padat Berupa Arang Bagasse. UPN "Veteran " Jatim, Hal. 9 - 11.

Yuniati A, Any S, dan Buchori A. (2013). Optimalisasi kondisi proses vulkanisasi terhadap sifat fisis kompon karet yang menggunakan bahan pengisi jenis silikat. Prosiding Seminar Nasional Kimia Surakarta. 